\section{Central serous chorioretinopathy: an update on pathogenesis and treatment}

M Gemenetzi ${ }^{1}$, G De Salvo ${ }^{1}$ and AJ Lotery ${ }^{1,2}$

Eye (2010) 24, 1743-1756; doi:10.1038/eye.2010.130; published online 8 October 2010

Keywords: central serous retinopathy; review; treatment

Introduction: a short historical review

Central serous chorioretinopathy (CSC) was first described by von Graefe in 1866, who named it as 'relapsing central luetic retinitis'. ${ }^{1}$ A variety of names have since been used to describe this idiopathic detachment of the neurosensory retina. ${ }^{2}$ In 1965 and 1967, the current terms of $\mathrm{CSC}^{3}$ and idiopathic central serous choroidopathy ${ }^{4}$ (ICSC) were first introduced to describe the same disease. The different terms adopted between 1866 and $1984^{5}$ reflect the lack of understanding of the pathophysiology of CSC.

Initially investigators tried to explain CSC aetiology and pathophysiology based on the psychogenic-related hypothesis proposed by Horniker in $1927 .{ }^{6}$ He suggested that angioneurotic patients were susceptible to retinal angiospasm and exudation in the macula.

Maumenee $^{7}$ was the first to describe a leak at the level of the retinal pigment epithelium (RPE) in 1965 using fluorescein angioscopy (FA). Subsequently, Gass ${ }^{4,8-11}$ provided detailed descriptions of the fluorescein angiographic characteristics of CSC.

Knowledge of the anatomy of the choriocapillaris-Bruch's membrane-RPE layer allowed ophthalmologists to surmise that there is a diffuse dysfunction of the RPE cells, the choroids, or both, ${ }^{12}$ regardless of the primary cause or the initiating event.

Infections, ${ }^{1,13-18}$ toxins, ${ }^{19-23}$ an immunological reaction, ${ }^{24-26}$ neuronal, ${ }^{2,27-31}$ circulatory, $^{32-34}$ and hormonal regulatory factors ${ }^{35-39}$ have all been
${ }^{1}$ Eye Unit, Southampton General Hospital, Southampton, UK

${ }^{2}$ Clinical Neurosciences Division, University of Southampton, Southampton, UK

Correspondence: A Lotery, Southampton Eye Unit, Southampton General Hospital, Tremona Road, Southampton, S016 6YD, UK.

Tel: + 440238079 4590; Fax: + 4402380794120 . E-mail: a.j.lotery@soton.ac.uk

Received: 30 March 2010 Accepted in revised form: 9 July 2010 Published online: 8 October 2010 
implicated in the initiation of the damaging process that leads to CSC.

As a result of the multiple theories and despite CSC having a favourable natural course, various treatments have been proposed. Psychotherapy was suggested in $1948,{ }^{40}$ followed by drug therapies such as $\alpha$-adrenergic blockade, ${ }^{41} \beta$-adrenergic inhibitors, ${ }^{42}$ and acetazolamide. ${ }^{43}$ Laser treatments have included retinal photocoagulation, ${ }^{44-47}$ transpupillary thermotherapy (TTT) ${ }^{48}$ and currently photodynamic therapy (PDT). ${ }^{49-53}$ More recently, anti-VEGF agents ${ }^{54-57}$ and corticosteroid antagonists $^{58,59}$ have also been investigated.

\section{Pathophysiology of CSC}

\section{Choroid dysfunction theory}

Gass $^{60}$ suggested that a focal increase in the permeability of the choriocapillaris was the primary cause of damage to the overlying RPE in patients with ICSC. He suggested that this could create detachment of the RPE, serous retinal detachment and, in $10-15 \%$ of patients, serofibrinous subretinal exudation.

Guyer et $\mathrm{l}^{32}$ suggested a potential model for the pathogenesis of CSC based on ICG-videoangiography (ICG-V). They noted diffuse hyperpermeability around active leakage sites seen with ICG-V but not with FA. Therefore they concluded that hyperpermeability was at the level of the choroid rather than the RPE. They proposed that choroidal hyperpermeability causes serous detachments of the RPE, which can induce a rip or decompensation of the RPE. This subsequently causes RPE leakage, that is, diffusion of water, electrolytes, and proteins that leads to a neurosensory retinal detachment.

Alterations in choroidal circulation may also cause choroidal ischaemia. This was first noted by Hayashi et $a l^{61}$ who used similar diagnostic equipment and found areas of choroidal ischaemia as well as leakage of ICG dye from the choriocapillaris. Fluorescein angiography (FA) and indocyanine green angiography (ICG-A) with a scanning laser ophthalmoscope and a digital imaging system were performed to evaluate choroidal circulation changes in CSC by Prunte and Flammer. ${ }^{33}$ In their study, dilated capillaries and dilated draining venules in one or more choroidal lobules, following a localised delay in arterial filling, might explain choroidal hyperpermeability in the area of the damaged RPE. These observations are suggestive of a localised lobular inflammatory or ischaemic choroiditis.

However, the cause of the choroidal abnormality is still unknown. The answer may lie in changes of the autoregulation in the choroidal blood flow. ${ }^{12}$

Tittl et al ${ }^{62}$ suggested a persistent abnormal regulatory response was involved in the pathogenesis of chronic CSC. They found that subfoveal choroidal blood flow regulation in patients with chronic CSC was impaired. This dysregulation occurred after substantial functional restoration at least 6 months after the last episode. Measurements of ocular fundus pulsation in patients with newly diagnosed active CSC have previously provided evidence that choroidal perfusion in the macular region might be abnormal. ${ }^{63}$

\section{RPE dysfunction theory}

An alternative theory suggests that CSC results from dysfunction of the RPE (Figures $1 a$ and $b$ ). This occurs following an undefined insult. It results in either a few impaired RPE cells or even a single RPE cell, which causes a reverse in fluid movement in a chorioretinal direction. This, in turn, leads to leakage of fluid in the subretinal space and finally to the development of a neurosensory retinal detachment. ${ }^{12}$ Spitznas ${ }^{64}$ suggested that focal damage to the RPE can reverse the direction of ion secretion and thus lead to greater fluid movement towards the retina than to the choroid.

A limitation of many theories of the aetiology of CSC is the lack of a suitable animal model to test hypotheses. In a rare example of the creation of an animal model of CSC, Negi and Marmor ${ }^{65}$ made small non-

rhegmatogenous retinal detachments (blebs) in rabbits over regions of RPE. The RPE was damaged mechanically or by laser photocoagulation. Focal RPE damage appeared to facilitate water movement from, rather than into, the subretinal space.

Marmor ${ }^{66}$ also postulated that there is a more diffuse RPE metabolic dysfunction and that a focal RPE 'leak' can overload the system so that the serous fluid accumulates and persists (Figure 2).

\section{Combined choroid and RPE dysfunction theory}

Alternatively there could be a combination of increased fluid leakage from the choriocapillaris and impaired RPE function. ${ }^{12}$ A persistent choriocapillaris abnormality could lead to prolonged stress of the RPE cells, which would not be able to pump in a retinochoroidal direction and therefore fluid would accumulate and cause a neurosensory detachment.

\section{Serous retinal detachment and pigment epithelial detachment associated with CSC}

Decompensation of the RPE in CSC results in neurosensory retinal detachment, serous pigment epithelial detachment (PED), and RPE atrophy. PED may result from any number of choroidal disorders that disrupt the normal junction between the basement membrane of the RPE and the inner collagenous layer of Bruch's membrane. Thus, serous fluid from the 

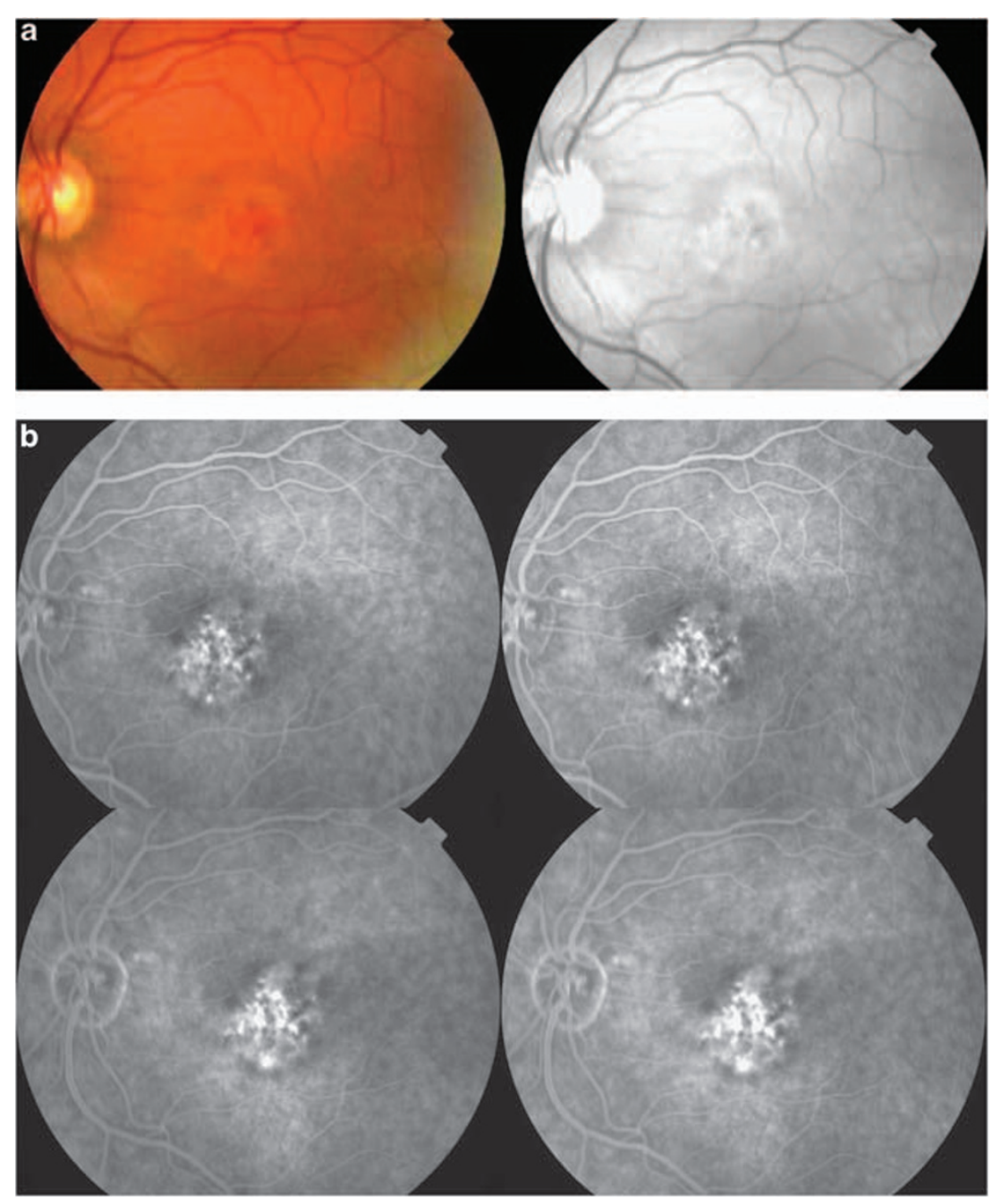

Figure 1 (a) Fundus and red-free photo of the left eye of a patient with recurrent idiopathic CSC associated with depigmentation of the RPE in the macular area as well as with small PEDs. (b) FFA of the above patient showing window defect and a focal RPE leak inferiorly to it.

underlying choriocapillaris gains access into the sub-RPE space. Fluorescein and ICG-A show early hyperfluorescence of the PED, which persists throughout the angiogram, demonstrating late pooling. Leakage into the sensory retina occurs only in cases of concurrent serous retinal detachment. Previously idiopathic serous detachment of the RPE was characterised as a 'benign' variant of idiopathic CSC, in terms of the final visual outcome, ${ }^{67-69}$ whereas in others the presence of PED was associated with poor visual recovery. ${ }^{69-71}$ The combination of PED and serous retinal detachment increases the probability of CSC diagnosis. Therefore, the definition of terms 'serous retinal detachment' and 'pigment epithelial detachment' is helpful in the understanding of CSC pathogenesis as well as of great importance for clinicians.

\section{CSC: a bilateral disease with systemic associations}

More recently, the use of three-dimensional optical coherence tomography (Fourier/spectral domain OCT) has helped investigators to study morphological alterations of the RPE both in symptomatic and asymptomatic eyes of the CSC patients. ${ }^{72-76}$ Not surprisingly, RPE irregularities, at the site of leakage, were noted in symptomatic eyes. ${ }^{76}$ However, Gupta et $a l^{77}$ studied three-dimensional single-layer RPE scans and also found that the majority of asymptomatic eyes of CSC patients also showed an uneven RPE surface. This finding was not present in control eyes of healthy volunteers. The authors postulated that accumulation of sub-RPE fluid along with RPE dysfunction, which results in the formation of RPE bumps, visible on 


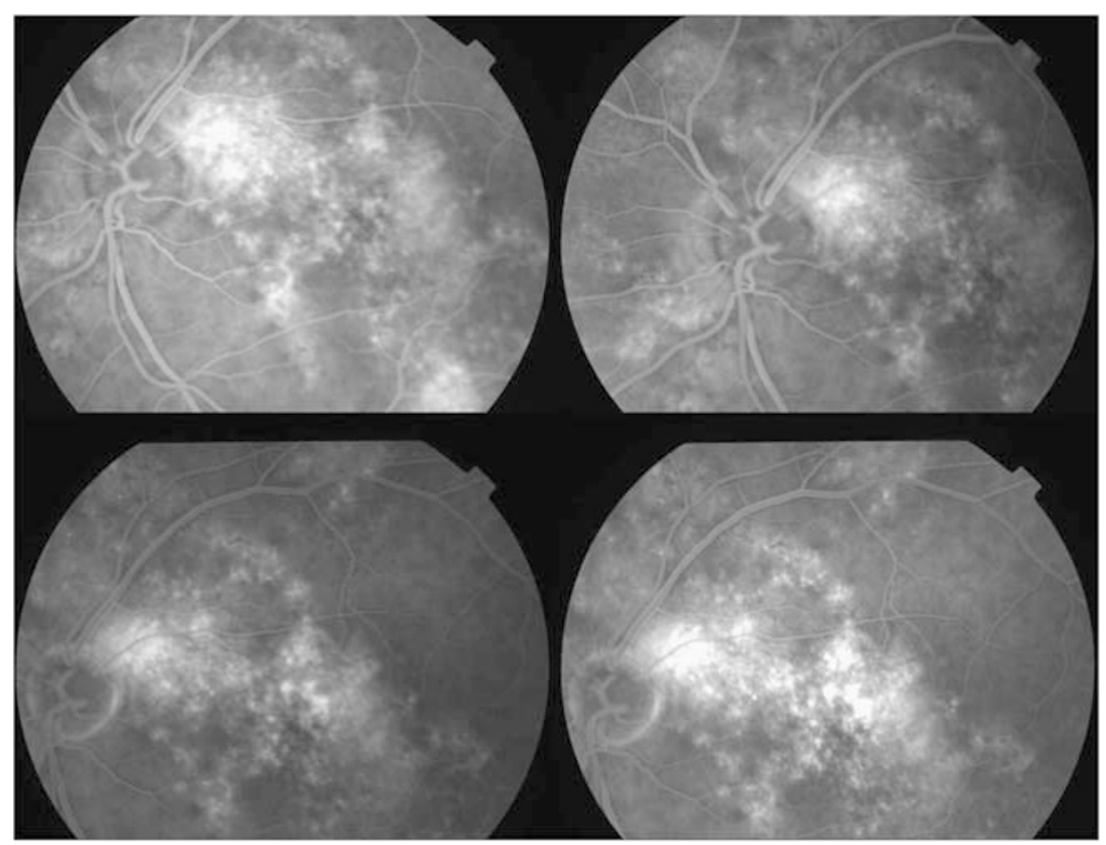

Figure 2 Multiple focal areas of staining (multiple zones of hyperfluorescence), more prominent in the juxtapapillary region, indicative of chronic ICSC, corresponding with areas of RPE atrophy, caused by recurrent serous retinal detachment.

spectral-domain OCT, may represent a preclinical or subclinical stage of the disease.

The above findings agree with previous observations, noted with multifocal electroretinogram (mERG) and ICG-V, respectively, that mERG changes and choroidal permeability changes are present in both affected and fellow eyes of CSC patients. ${ }^{78,79}$

The first systematic investigation of the relationship between a type A behaviour pattern (quickness to anger, competitiveness, and need to be in control) and macular disease was conducted by Yannuzzi. ${ }^{2}$ This was the first cross-sectional study that employed strict clinical definitions and matched controls to assess CSC patients to classify them as a type A behaviour pattern. The latter was statistically more frequent in CSC patients than in both the control groups used in this study.

Experimental evidence to support the relationship of type A behaviour and CSC was provided by Yoshioka et al a few years before Yannuzzi's investigation. The authors observed that intravenous epinephrine produced experimental CSC. They also suggested that the serous detachment of the neurosensory retina in CSC was biochemically mediated via stimulation of adrenergic receptors; this resulted in choriocapillaris hyperpermeability and degeneration of the RPE cells above the damaged endothelial cells. ${ }^{30,31,80}$

The above clinical and experimental evidence demonstrated an association of the disease with a sympathetic response. Unfortunately treatment of the disorder based on these observations has not proven helpful. However, these papers do illustrate the systemic associations of CSC.

\section{Role of corticosteroids in the development of CSC}

Jampol et $a l^{81}$ stated that corticosteroids might sensitise the choroidal blood vessels or RPE to the effects of endogenous catecholamines.

There is clinical and experimental evidence that corticosteroid intake contributes to the development of CSC. ${ }^{35-39}$ Central serous chorioretinopathy induced by the systemic use of steroids was first reported in $1984 .^{35}$ Almost 20 years later, Carvalho-Recchia et $a l^{82}$ published the first report of a consecutive series of patients with acute CSC studied prospectively for an association with corticosteroids. They found a statistically significant difference in corticosteroid exposure between study patients and controls. In addition, CSC has been described in patients with endogenously high levels of corticosteroids (Cushing's syndrome, pregnancy, and stress $)^{39}$ as well as in patients with hypercortisolism due to the treatment of ocular (optic neuritis, ischaemic optic neuropathy, solar retinopathy, scleritis, anterior uveitis, and chorioretinitis $)^{83-88}$ or systemic diseases. ${ }^{89,90}$ Bouzas et $a l^{91}$ suggested a category of systemic diseases that have been associated with CSC only in cases where glucocorticoids were used (such as asthma, allergic rhinitis, sinusitis, myasthenia, back pain, hepatitis, and breast cancer). They postulated that glucocorticoid intake 
in these cases was more important for the development of CSC than the underlying disease itself.

Many components of the hypothalamus-pituitaryadrenal axis and the autonomic (sympathetic) nervous system have been implicated in the pathogenesis of CSC. ${ }^{92,93}$ In an attempt to identify endocrine and metabolic abnormalities in patients with CSC, Haimovici et $a l^{94}$ prospectively evaluated serum and urinary catecholamines, glucocorticoids, mineralocorticoids, serum testosterone, and thyroid-stimulating hormone function of 24 CSC patients. They found that $50 \%$ of patients with active acute CSC had an elevated 24-h urine cortisol or tetrahydroaldosterone levels.

At the cellular level, glucocorticoids have been shown to increase the expression of $\beta$-adrenergic receptors. ${ }^{95} \mathrm{At}$ the molecular level, the same authors provided evidence linking glucocorticoid effects of $\beta$-adrenergic receptors to an increase in receptor mRNA. Sakaue and Hoffman ${ }^{96}$ found that the expression of the $\alpha-1 \mathrm{~B}$-adrenergic receptor gene is induced by glucocorticoids and results in an increase in the number of $\alpha$-1B-adrenergic receptors.

There is evidence of the influence of corticosteroids on adrenergic receptor gene transcription and expression, which represents the genomic effects of corticosteroids mediated by intracellular receptors.

Important neural effects of glucocorticoids are also exerted by non-genomic mechanisms. This may explain the delay in the expression of genomic effects. ${ }^{97}$ Some of the glucocorticoid receptors that mediate the nongenomic effects are localised in the cell membrane. These include ion channels and neurotransmitter receptors. ${ }^{97}$ Jampol et $a l^{81}$ linked the rapid onset of the non-genomic effects of corticosteroids to the occurrence of serous retinal detachments after the use of high-dose systemic corticosteroids.

\section{Evidence of familial clustering of CSC}

Weenink et al reported 27 patients with characteristic, mostly bilateral, fundus lesions of chronic CSC. Out of 80 investigated relatives, 35 (44\%) had fundus lesions: 22 had chronic CSC in one eye, 20 of them had chronic CSC or RPE atrophy in the fellow eye; 13 relatives had RPE atrophy in one or both eyes. ${ }^{98}$ The mode of inheritance could not be established. Fawzi et a ${ }^{99}$ described the demographic and clinical characteristics of CSC after solid organ transplantation. One of their patients with the severe variant of CSC with bullous retinal detachment and a cardiac transplant had two second-degree cousins who carried the diagnosis of Vogt-Koyanagi-Harada syndrome. This syndrome has similarities to the severe variant of CSC with bullous retinal detachment. According to the investigators, this observation raised the possibility of an underlying predisposition in these patients that might have been genetically determined.

\section{Pathogenesis of visual loss in CSC patients}

Foveal attenuation, cystoid macular degeneration, and damage of the foveal photoreceptor layer cause visual loss in CSC. ${ }^{48,100,101}$ Cystoid macular degeneration, which is generally known as chronic macular oedema, was defined by lida et $a l^{100}$ as cystoid spaces without intraretinal fluorescein leakage in the fovea.

Posterior cystoid retinal degeneration, generally known as RPE atrophy or decompensation or depigmentation, is defined as cystoid retinal degeneration located in the posterior pole, sparing the fovea. ${ }^{102}$ Duration of symptoms more than 5 years and subretinal fibrosis have been identified as risk factors for the development of posterior cystoid retinal degeneration in CSC, but this is not necessarily associated with marked reduction in visual acuity. ${ }^{103}$ On the contrary, there are cases of foveal atrophy associated with severe visual loss in long-standing serous macular detachment without any cystoid changes in the retina. ${ }^{101}$

One intriguing feature of CSC is the ability of photoreceptors to continue to function above a serous retinal detachement. This compares to the profound visual loss associated with rhegmatogenous retinal detachment. Experimental studies of retinal detachment have suggested that retinal detachment has a greater impact on cones than on rods. ${ }^{104,105}$ The OCT studies have confirmed that photoreceptor changes are more prominent at the fovea. ${ }^{101}$ However, the same authors observed that there was a much longer survival of photoreceptors in CSC. This, they explained on the basis of differences between the pathophysiological conditions underlying the neuroretinal damage in CSC patients and the behaviour of experimental animal models.

Conversely, Chuang et al ${ }^{106}$ suggested that rod dysfunction was more pronounced than cone dysfunction in CSC. Mori et al ${ }^{107}$ declared that photopigment degeneration appears to take place in the rod photoreceptors of the detached retina. Wang et al ${ }^{108}$ postulated that visual dysfunction should be more evident under scotopic conditions because the RPE visual cycle subserves predominantly the rods whereas a separate visual cycle in the neurosensory retina supports cone function. ${ }^{109}$

\section{CSC impact on vision in untreated eyes}

Visual acuity usually recovers well in untreated eyes affected with CSC. ${ }^{110}$ However, quality of vision may be affected. ${ }^{111}$ Patients with resolved CSC may complain of metamorphopsia, decrease in brightness, and alteration 
in colour vision in the affected eye for several months. ${ }^{4}$ Wong et $a l^{112}$ concluded that ophthalmologists used to 'trivialize the situation as patients sometimes suffer the consequences following presumed resolution of the disease'. They also found a strong correlation, although statistically insignificant, of visual acuity and contrast sensitivity in both normal and ICSC-affected eyes in their long-term follow-up of resolved ICSC. Koskela et $a l^{113}$ found a statistically significant correlation between visual acuity and contrast sensitivity after resolution of ICSC.

Therefore, clinicians need to be aware that patients may still be visually symptomatic despite visual acutiy returning after an episode of ICSC.

\section{Treatment of CSC}

\section{Types of CSC and treatment criteria}

The literature does not really distinguish well between what one might call 'acute CSC' and 'chronic CSC', although there is a general belief that such a distinction would correlate with the long-term visual prognosis as well as the decision of whether to treat or wait and when to start treatment.

The term acute CSC usually refers to the self-limiting CSC that resolves spontaneously over a few months without any treatment and minimal residual changes on imaging. Most clinicians would agree with the definition that Spaide et al $^{114}$ gave to chronic CSC, meaning a serous macular elevation, visible biomicroscopically or detected by OCT, that is associated with RPE atrophic areas and subtle leaks or ill-defined staining by FA. Polak et $a l^{36}$ noted that the major distinction between chronic and acute disease is the fact that chronic disease has widespread pigment epithelial changes without overt detachment in most cases, whereas in acute disease there is focal pigment epithelial abnormality and marked detachment.

Diffuse RPE or sick RPE syndrome is a term that has been defined in literature as chronic CSC by some investigators $^{36}$ or as a form of chronic CSC by others. ${ }^{50}$ It has been reported as an idiopathic condition ${ }^{50}$ or as a complication of systemic corticosteroid treatment. ${ }^{36}$ Its natural course is favourable despite the remaining problems in colour vision and some degree of metamorphopsia. The use of any of the treatment forms available today, which we describe further in this article, is questionable, especially in corticosteroid induced disease that recovers well when steroid daily dosage is diminished.

Bullous serofibrinous exudative retinal detachment occurs in some patients with ICSC. Owing to its peculiar clinical findings, it can present a diagnostic dilemma and may lead to inappropriate diagnosis of rhegmatogenous RD or serous RD because of other causes. ${ }^{115}$

Corticosteroid therapy, organ transplantation, haemodialysis, and pregnancy have been reported to relate to this form of CSC. It has been described however as an idiopathic CSC form as well. ${ }^{116-118}$ In the largest case series of ICSC with spontaneous bullous exudative $\mathrm{RD}$, visual prognosis was good without any treatment. ${ }^{115}$

Photoreceptor atrophy in the fovea, despite successful reattachment, occurs after duration of symptoms of approximately 4 months. ${ }^{47}$ Attenuation of the foveal photoreceptor layer is associated with permanent visual loss as mentioned above. Imminent damage of foveal photoreceptors or foveal atrophy defined by the combination of chronic CSC signs with current activity involving or immediately threatening the fovea could be considered as the high-risk group for which treatment should be applied.

Therefore, treatment should be considered in recurrent chronic CSC or a single CSC episode, of greater than 3 months duration, with some signs of chronic CSC.

Previous permanent visual loss in the fellow eye caused by a similar procedure would also indicate that treatment should be instituted even in the absence of chronic CSC signs or even if foveal photoreceptors were not immediately threatened.

\section{Previous pharmacological and other treatment suggestions}

Before the development of other treatments, psychotherapy was suggested as a therapy. ${ }^{40}$ It was abandoned though as soon as there was progress in the understanding of the pathogenic nature of the disease.

Corticosteroids were presented as the only treatment choice in CSC several years ago. They were administered subconjuctivally or systemically, but are no longer recommended as knowledge of CSC pathogenesis has evolved. ${ }^{119-121}$

Adrenocorticotropic hormone, ${ }^{119}$ anti-inflammatory drugs, ${ }^{122}$ retrobulbar tolazoline injections, ${ }^{123}$ subconjuctival injections of milk, albumin and salt solutions, anti-syphilitic and anti-tubercular drugs, insulin-free pancreatic extract, and thyroid extract have all also been suggested in the past. ${ }^{124}$ The use of the above agents was not proven to be effective by any clinical trials. ${ }^{2}$

The role of stimulation of adrenergic receptors in the pathogenesis of CSC led some investigators to suggest that $\beta$ - or $\alpha$-adrenergic blockade could be utilised in the treatment of CSC. ${ }^{41,42}$ Their suggestions were based on small case series of patients and experimental models. However, there is no significant proof to support such a therapeutic approach. 
Acetazolamide has also been tried as a means of treatment of the chronic macular oedema caused by CSC or other chorioretinal diseases with short-term encouraging results but no evidence of long-term benefit. $^{43}$

\section{Current and future treatment options for CSC}

Natural course of CSC and the use of argon laser photocoagulation

Focal photocoagulation of the leakage sites does not have a significant effect on visual acuity. ${ }^{124-127}$ Robertson and Ilstrup ${ }^{127}$ suggested a reduction in CSC recurrences and shortening of the duration of detachment with direct laser photocoagulation compared with sham or indirect (away from the site of leakage) photocoagulation within a follow-up period of 18 months. Dellaporta ${ }^{128}$ concluded that untreated eyes were 3.3 times more likely to develop a recurrence than treated eyes. Gilbert et $a l^{129}$ found no difference either in final visual acuity or in recurrence rate between eyes treated with argon laser photocoagulation and untreated eyes in their retrospective long-term follow-up study of CSC patients.They also explained discrepancies in recurrence rates in various studies by the different follow-up durations and different treatment techniques (laser spot size).

Wang et $a l^{130}$ recommended early laser photocoagulation treatment in detachments that have lasted longer than duration of symptoms, suggested by the presence of subretinal granular deposits. Robertson ${ }^{131}$ suggested early laser photocoagulation in cases with visual acuity of 20/40 or less and multiple recurrences.

In the study, with the longest follow-up (6-12 years), argon laser photocoagulation treatment was not shown to reduce the incidence of recurrent disease or of chronic CSC. This study also showed that the role of argon laser photocoagulation in CSC with good visual acuity is limited to hastening relief of symptoms by achieving speedier resolution of serous detachment. ${ }^{132}$

Overall, a review of literature on argon laser photocoagulation for CSC suggests that this treatment is mainly effective in acute CSC with obvious focal leakage observed on FA. In these cases an earlier resolution of the serous detachment is achieved compared with natural history. However, if the area of leakage is subfoveal or juxtafoveal, photocoagulation may induce secondary choroidal neovascularisation (CNV) and/or of damage foveal photoreceptors. ${ }^{108}$ Therefore other treatment options appear safer.

\section{Discontinuation of corticosteroids}

Sharma et al $^{133}$ reported an observational case series of atypical severe CSC treated with corticosteroids for their ocular condition. Discontinuation of corticosteroids resulted in reattachment of the retina in $88 \%$ of affected eyes. They concluded that discontinuation of corticosteroids in atypical CSC could lead to obliteration of RPE leaks and retinal reattachment without laser treatment.

\section{Transpupillary thermotherapy}

Shukla et al ${ }^{48}$ performed TTT in long-standing CSC, which resulted in the resolution of CSC with subfoveal angiographic leaks and significant improvement in visual outcome, in comparison with the natural history of persistent CSC. Long-term results are unknown.

\section{Photodynamic treatment with verteporfin}

Photodynamic therapy with verteporfin has recently been utilised to treat ICSC. Photodynamic treatment using verteporfin has both an occlusive effect on $\mathrm{CNV}$ and also affects normal choroidal perfusion. ${ }^{134}$ Chan et $a l^{53}$ postulated that PDT could be beneficial for the treatment of CSC by its effect on the structure of choroidal vasculature, causing alterations in choroidal permeability.

Both Fluorescein and ICG-A-guided PDT have been recommended for treatment of ICSC. Choroidal abnormalities, demonstrated on ICG-A, imply that treatment can be guided by ICG-A. ${ }^{53}$

It has also been also suggested that PDT acts by both decreasing choroidal hyperpermeability and by tightening the blood-retinal barrier at the level of the RPE. Therefore, other investigators believe that treatment directed at the area of RPE decompensation on FA can be adequate to allow subretinal fluid resolution. ${ }^{135}$

Choroidal hypoperfusion, which is the main mechanism of action of PDT in CSC, can also lead to complications, especially if conventional PDT is performed, according to the Treatment of age-related macular degeneration with Photodynamic Therapy Study guidelines. ${ }^{136}$ Lee et $a l^{137}$ described three cases of abrupt visual loss due to severe choroidal ischaemia after using standard PDT in CSC patients. RPE atrophy, juxtafoveal $\mathrm{CNV}$, and transient reduction in macular function demonstrated by mERG led investigators to reconsider PDT parameters for the treatment of CSC. ${ }^{51,53,138,139}$

Lai et $a l^{140}$ reduced the dosage of verteporfin and shortened the interval between infusion and laser application to induce choroidal vascular remodelling and minimise any collateral damage to adjacent retinal structures. The safe and beneficial effect of 'safety enhanced' (half-dose verteporfin)-PDT was demonstrated in both acute and chronic CSC by the same investigators. ${ }^{141,142}$ Zhao et al $^{143}$ suggested that $30 \%$ of 
verteporfin full dose was the effective lowest dose in the treatment of their acute CSC patients.

Reibaldi et al $^{144}$ described two cases of long-standing CSC treated with ICG-A-guided low-fluence PDT. The anatomic and functional outcomes were encouraging. They concluded that ICG-A-guided low-fluence PDT seemed effective and safe for treating long-standing chronic CSC. The same investigators studied the efficacy of ICG-guided low-fluence PDT compared with standard PDT in a prospective non-randomised clinical trial; both standard-fluence PDT and low-fluence PDT resulted in complete subretinal fluid reabsorption with visual acuity improvement. They postulated that choroidal hypoperfusion related to PDT could be reduced by low-fluence PDT. ${ }^{145}$

Recently, Inoue et $a l^{146}$ shortened the irradiation time and reduced the total energy using the same light intensity and the same verteporfin dosage as the standard protocol. They reported that the success rate of PDT for CSC depends on the degree of hyperfluorescence seen on ICG-A. PDT is not effective or the recurrence rate is predicted to be high in eyes without intense hyperfluorescence.

Long-term efficacy from this form of treatment is unknown. In addition, the number of patients in most of the relevant studies is limited and often there is no dramatic improvement in terms of the functional outcome of the treatment despite impressive anatomic outcomes observed with OCT. Additionally, using conventional PDT, visual improvement may be limited in patients with prolonged symptom duration, in those who have baseline confluent RPE atrophy, disintegrity of the junction between foveal outer and inner photoreceptor layer or progression of RPE atrophy after PDT. The risk of PDT-induced foveal injury in these patients should also be considered. ${ }^{147}$

As far as direct comparison of laser photocoagulation with PDT treatment is concerned, we now have some results coming from study by Maruko et al, ${ }^{148}$ in which authors showed that the choroidal thickness and hyperpermeability seen during ICG-A was reduced after PDT. They suggested that PDT reduces the choroidal vascular hyperpermeability seen in CSC and it may act by a different mechanism than laser photocoagulation.

Most published studies suggest PDT with verteporfin is a safe and efficacious treatment even in chronic CSC and that complications are rare. This is especially true when PDT parameters are changed to minimise potential damage. Unlike argon laser photocoagulation, it can be performed for subfoveal leakage (Figure $3 a$ and $b$ ).

\section{Intravitreal bevacizumab}

A hypothesis that VEGF antibodies could reduce choroidal hyperpermeability and choriocapillaris ischaemia associated with $\mathrm{CSC}^{55}$ has resulted in treatment of acute and chronic forms of CSC with intravitreal injections of bevacizumab (Avastin). ${ }^{54-57}$

However, all of the related reports are small, uncontrolled case series with a short duration of follow-up. Larger, controlled trials are still needed to evaluate the efficacy and safety of anti-VEGF agents for this indication.

\section{Micropulse diode laser photocoagulation}

Subthreshold micropulse diode laser $(810 \mathrm{~nm})$ has recently been assessed for the treatment of chronic CSC. ${ }^{149-152}$ To avoid retinal damage, caused by conventional laser photocoagulation, it has been used in chronic CSC, in eyes with either well-defined leaking sites or diffuse leakage.

In the largest of these case series (26 eyes), a gain of visual acuity of three lines or more was achieved in $58 \%$ and a gain of between one and three lines was achieved in $23 \%$ of the treated eyes. ${ }^{149}$ Ricci et al ${ }^{150}$ assessed the efficacy of indocyanine green-enhanced subthreshold micropulse diode laser photocoagulation and found no worsening of the serous detachment or of visual acuity in patients with incomplete recovery at 12 months.

Subthreshold micropulse diode laser photocoagulation therefore appears to be a safe form of treatment in chronic CSC. Results however are not superior to PDT. Furthermore, micropulse diode laser photocoagulation seems unsuitable for diffuse leakage and diffuse RPE decompensation. These are frequent findings in chronic CSC cases. Larger, controlled, randomised clinical trials are needed to establish the role of diode laser photocoagulation in the treatment of CSC. Currently this treatment may be considered as an alternative to PDT for eyes with focal and well-defined areas of leakage.

\section{Corticosteroid antagonists}

Jampol et $a l^{81}$ first suggested that glucocorticosteroid antagonist activity may be of value in preventing or treating episodes of CSC. This was based on the association of endogenous hypercortisolism with the development of CSC. ${ }^{39}$ The potential treatment of CSC episodes using antiglucocorticoid agents includes RU486 (mifepristone) and ketoconazole.

RU486 is an active anti-glucocorticosteroid and antiprogesterone agent. This dual action results from similarities between receptors involved. ${ }^{153}$ Its use in voluntary early pregnancy termination has delayed the initiation of ophthalmic clinical trials in the United States.

Ketoconazole is also an adrenocorticoid agent. It was first tested as a potential treatment for CSC by Golshahi et $a l^{58}$ in a prospective, case-controlled study. Patients received $200 \mathrm{mg}$ of the drug per day for 4 weeks. 

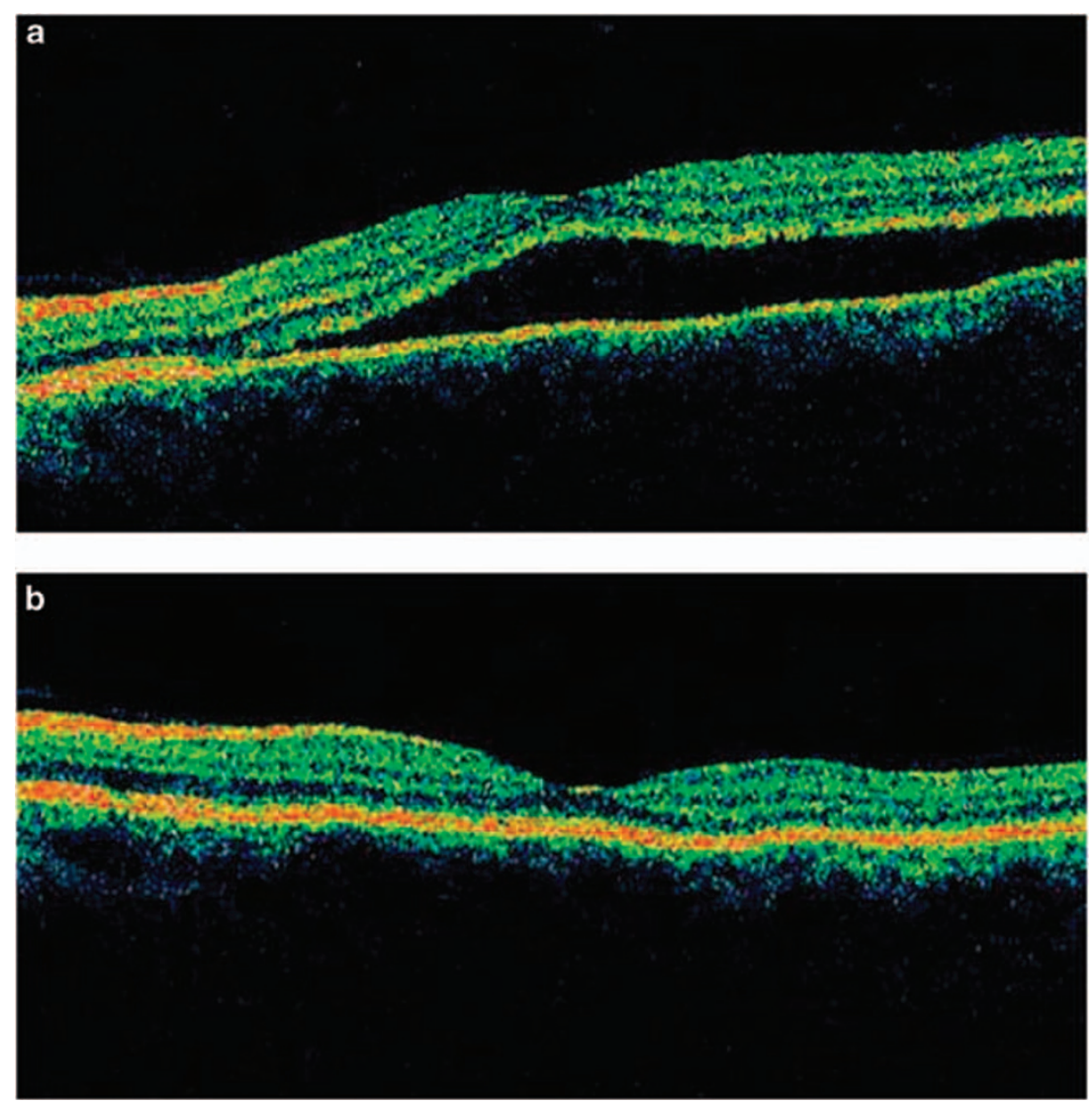

Figure 3 (a) OCT image of a CSC patient prior to photodynamic treatment showing a large amount of subretinal fluid involving the fovea. (b) OCT image of the same patient 3 months after half-dose photodynamic treatment showing complete resolution of subretinal fluid.

The clinical benefit of this trial was not statistically significant. After 3 years, an increase in dosage of ketoconazole to $600 \mathrm{mg}$ daily for 4 weeks was tried by Meyerle $e t a l^{59}$ who found a delayed therapeutic response at 8 weeks after initiation of treatment. They postulated that their inconclusive results were because of short duration of treatment or/and normal baseline cortisol levels of the patients involved and they suggested larger, controlled trials to test the efficiency of ketoconazole in CSC patients.

\section{Aspirin}

Caccavale et al $^{154}$ evaluated low-dose acetyl salicylic acid (aspirin) in 107 CSC patients with a mean follow-up time of 20 months. They found a rapid recovery of visual acuity and a reduced number of recurrences in their patients. They surmised that in all the diseases, associated with CSC, plasminogen activator inhibitor-1 (PAI-1) was increased and that aspirin is effective in lowering PAI-1 levels and platelet aggregation.

\section{Search strategy}

We searched the MEDLINE/PubMed database for articles from March 1969 to January 2010 after following
MeSH suggestions for articles including the terms: CSC, chorioretinopathies, and central serous retinopathies. The headline used to locate related articles in PubMed was 'central serous chorioretinopathy' and to restrict search we used the headlines 'pathophysiology of central serous chorioretinopathy', 'treatment of central serous chorioretinopathy', and 'photodynamic treatment in central serous chorioretinopathy'. A manual search was also based on references from these articles as well as review articles.

\section{Comments}

After reviewing the voluminous literature on the aetiology and pathogenesis of CSC it certainly seems that CSC is a multifactorial disease. It appears to result from a complex interaction of known and unknown environmental and genetic factors. This ultimately leads to a bilateral disease with systemic associations.

In 1986, Yannuzzi ${ }^{2}$ stated there was a lack of a definitive, universally accepted treatment for CSC. This could also be stated today. The multifactorial aetiology and complex pathophysiology of the disease and its generally favourable natural history provide no clear 
proof of the necessity and long-term efficacy of any of the treatment choices that have been reviewed in this article. Further large, prospective or even retrospective longterm follow-up studies are required to decide on one or more safe and effective forms of treatment, which will be generally accepted by clinicians.

Until then, it seems reasonable to suggest reduced dose/fluence/irradiation time verteporfin PDT in recurrent chronic CSC or in single CSC episodes, not resolving for a period of at least 3 months, accompanied by signs of chronic CSC. In both of which there is active leakage involving the fovea or a juxtafoveal area. Micropulse diode laser treatment, applied on welldefined leaking sites, can be considered as an alternative. The use of corticosteroid antagonists, possibly after evaluation of patients' cortisol profile (for example, urine cortisol or tetrahydroaldosterone levels), is an interesting future option that merits further investigation. In addition, counselling about discontinuation of steroid treatment for systemic or ocular conditions and explanation of the relation of the disease to stress is helpful in the management of CSC patients.

\section{Conflict of interest}

The authors declare no conflict of interest.

\section{References}

1 Von Graefe A. Kurzere Abhandlungen. Notizen und casaistische Mitheilungen vermischten Inhalts: VI. Ueber zentrale recidivirende Retinitis. Albrecht Von Graefes Arch Klin Exp Ophthalmol 1866; 12: 211-215.

2 Yannuzzi LA. Type-A behaviour and central serous chorioretinopathy. Retina 1987; 7: 111-130.

3 Klein B. Macular diseases: clinical manifestations. Central serous retinopathy and chorioretinopathy. Trans Am Acad Ophthalmol Otorynolaryngol 1965; 69: 614-620.

4 Gass JDM. Pathogenesis of disciform detachment of the neuroepithelium: II. Idiopathic central serous choroidopathy. Am J Ophthalmol 1967; 63: 587-615.

5 Yannuzzi LA, Shakin J, Fisher Y, Altomonte MA. Peripheral retinal detachment and retinal pigment epithelial atrophic tracts secondary to central serous pigment epitheliopathy. Ophthalmology 1984; 91: 1554-1572.

6 Horniker E. Su di unaforma di retinite centrale di origine vasoneurotica. Ann Ottalmol 1927; 55: 578-600, 830-840, 865-883.

7 Maumenee AE. Symposium on macular diseases: clinical manifestations. Trans Am Acad Ophthalmol Otolaryngol 1965; 69: 605-613.

8 Gass JDM. Pathogenesis of disciform detachment of the Neuroepithelium: I. General concepts and classifications. Am J Ophthalmol 1967; 63: 573-585.

9 Gass JDM. Pathogenesis of disciform detachment of the neuroepithelium: III. Senile disciform macular degeneration. Am J Ophthalmol 1967; 63: 617-644.
10 Gass JDM. Pathogenesis of disciform detachment of the neuroepithelium: IV. Fluorescein angiographic study of senile disciform macular degeneration. Am J Ophthalmol 1967; 63: 645-659.

11 Gass JDM. Pathogenesis of disciform detachment of the neuroepithelium: V. Disciform macular detachment secondary to focal choroiditis. Am J Ophthalmol 1967; 63: 661-687.

12 Ryan SJ. Central serous chorioretinopathy. Retina 3rd edn. 2001; 2: 1153-1181.

13 Fuchs E. Ein Fall von zentraler residivierender syphilitischer Netzhaut Enzundung. Zentralbl Prakt Augenheilkd 1916; 40: 105-108.

14 Guist G. Ueber preretinales Oedema. Z Augenheilkd 1925; 54: 37-49.

15 Kitahara S. Ueber klinische Beobachtungen bei der in Japan haufig vorkommenden Chorioretinitis sentralis serosa. Klin Monatsbl Augenheilkd 1936; 97: 345-362.

16 Reiger H. Zur Atiologic der Retinitis exudative externa centralis. Albrecht Von Graefes Arch Klin Exp Ophthalmol 1960; 00: 000-000.

17 Djakri SE, Dilinas N. L'importance de la lambliase comme facteur etiologique dans la chorioretinite centrale sereuse. Ophthalmologica 1963; 147: 264-272.

18 Si-Boen-Lian. The etiologic agent of central serous central chorioretinitis. Ophthalmologica 1964; 148: 263-267.

19 Ko HU. An experimental study of the nature of Masuda's chorioretinitis: III. A study of the relationship existing between chorioretinitis centralis photodynamica and the function of the kidney. Acta Soc Ophthalmol Jpn 1934; 38: 1060-1073.

20 Redman SI. A review of solar retinitis as it may pertain to macular lesions seen in persons of the armed forces. Am J Ophthalmol 1945; 28: 1155-1165.

21 Delman M, Leubuscher K. Transient macular edema due to griseofulvin. Am J Ophthalmol 1963; 56: 658.

22 Haynes SB, Levine S, Scotch NA, Feinleib M, Kannel WB. The relationship of psychological factors to coronary heart disease in the Framingham Study: I. Methods and risk factors. Am J Epidemiol 1978; 107: 362-383.

23 Burton T. Central serous retinopathy. In: FC Blodi (ed) Current Concepts in Ophthalmology. St Louis: CV Mosby, 1972, pp 1-28.

24 Bettman JW. Allergic retinosis. Am J Ophthalmol 1945; 28: 1323-1328.

25 Lothman L. Clinical Manifestations of Allergy in Ophthalmology Year Book of EENT. Year Book Medical Publishers: Chicago, 1941, pp 38-41.

26 Berens C, Sayad WY, Girard LJ. Symposium on ocular allergy. The uveal tract and retina: consideration of certain experimental and clinical concepts. Trans Am Acad Ophthalmol Otolaryngol 1952; 56: 220-241.

27 Hassan L, Carvalho C, Yannuzzi LA, Iida T, Negrão S. Central serous chorioretinopathy in a patient using methylenedioxymethamphetamine (MDMA) or 'ecstasy'. Retina 2001; 21: 559-561.

28 Nagayoshi K. Experimental study of chorioretinopathy by intravenous injection of adrenaline. Nippon Ganka Gakkai Zasshi 1971; 75: 1720-1727.

29 Miki T, Sunada E, Higaki T. Studies on chorioretinitis induced in rabbits by stress (repeated administration of epinephrine). Nippon Ganka Gakkai Zasshi 1972; 76: 1037-1045.

30 Yoshioka H, Sugita T, Nagayoshi K. Fluorescein angiographic findings in experimental retinopathy 
produced by intravenous adrenaline injection. Preliminary report. Nippon Ganka Kiyo 1970; 21: 648-652.

31 Yoshioka H, Katsume Y, Akune H. Experimental central serous chorioretinopathy in monkey eyes: fluorescein angiographic findings. Ophthalmologica 1982; 185: 168-178.

32 Guyer DR, Yannuzzi LA, Slakter JS, Sorenson JA, Allen H, Orlock D. Digital indocyanine-green videoangiography of central serous chorioretinopathy. Arch Ophthalmol 1994; 112: 1057-1062.

33 Prunte C, Flammer J. Choroidal capillary and venous congestion in central serous chorioretinopathy. $A m \mathrm{~J}$ Ophthalmol 1996; 11: 26-34.

34 Giovannini A, Scassellati-Sforzolini B, D'Altobrando et al. Choroidal findings in the course of idiopathic serous pigment epithelial detachment detected by indocyanine green videoangiography. Retina 1997; 17: 286-293.

35 Wakakura M, Ishikawa S. Central serous chorioretinopathy complicating systemic corticosteroid treatment. Br J Ophthalomol 1984; 68: 329-331.

36 Polak BCP, Baarsma GS, Snyers B. Diffuse retinal pigment epitheliopathy complicating systemic corticosteroid treatment. Br J Ophthalomol 1995; 79: 922-925.

37 Heimovici R, Gragoudas ES, Duker JS, Sjaarda RN, Eliott D. Central serous chorioretinopathy associated with inhaled or intranasal corticosteroids. Ophthalmology 1997; 104: $1653-1660$.

38 Garg SP, Dada T, Talwar D, Biswas NR. Endogenous cortisol profile in patients with central serous chorioretinopathy. Br J Ophthalomol 1997; 81: 962-964.

39 Bouzas EA, Scott MH, Mastorakos G, Chrousos GP, KaiserKupfer MI. Central serous chorioretinopathy in edogenous hypercortisolism. Arch Ophthalmol 1993; 111: 1229-1233.

40 Harrington DO. Psychosomatic interrelationship in ophthalmology. Am J Ophthalmol 1948; 31: 1241-1251.

41 Yoshioka $\mathrm{H}$. The etiology of central serous chorioretinopathy. Nippon Ganka Gakkai Zasshi 1991; 95: 1181-1195.

42 Avci R, Deutman AF. Die Behandlung der zentralen serösen Choroidopathie mit dem Betarezeptorenblocker Metoprolol (Vorläufige Ergebnisse). Klin Monatsbl Augenheilkd 2005; 202: 199-205.

43 Gonzalez C. Décollements séreux retiniens. J Fr Ophthalmol 1992; 15: 529536.

44 Robertson DM, Ilstrup D. Direct, indirect and sham laser photocoagulation in the management of central serous chorioretinopathy. Am J Ophthalmol 1983; 95: 457-466.

45 Burumcek E, Mudun A, Karakocoglu S, Arslan MO. Laser photocoagulation for persistent central serous retinopathy: results of lonf term follow-up. Ophthalmology 1997; 104: 616-622.

46 Yap EY, Robertson DM. The long-term outcome of central serous chorioretinopathy. Arch Ophthalmol 1996; 114: 689-692.

47 Wang MS, Sander B, Larsen M. Retinal atrophy in idiopathic central serous chorioretinopathy. Am J Ophthalmol 2002; 133: 787-793.

48 Shukla D, Kolluru C, Vignesh TP et al. Transpupillary thermotherapy for subfoveal leaks in central serous chorioretinopathy. Eye 2006; 22: 100-106.

49 Battaglia Parodi M, Da Pozzo S, Ravalico G. Photodynamic therapy in chronic central serous chorioretinopathy. Retina 2003; 23: 235-237.

50 Canakis C, Livir-Rallatos C, Panayiotis Z, Livir-Rallatos G, Persidis E, Conway MD et al. Ocular photodynamic therapy for serous macular detachment in the diffuse retinal pigment epitheliopathy variant of idiopathic central serous chorioretinopathy. Am J Ophthalmol 2003; 136: $750-752$.

51 Cardillo Piccolino F, Eandi CM, Ventre L, Rigault de la Longrais RC, Grignolo FM. Photodynamic therapy for chronic central serous chorioretinopathy. Retina 2003; 23: 752-763.

52 Yannuzzi LA, Slakter JS, Gross NE, Spaide RF, Costa DL, Huang SJ. Indocyanine green angiography- guided photodynamic therapy for treatment of chronic central serous chorioretinopathy: a pilot study. Retina 2003; 23: 288-298.

53 Chan WM, Lam DS, Lai TY, Tam BS, Liu DT, Chan CK. Choroidal vascular remodelling in central serous chorioretinopathy after indocyanine green angiography guided photodynamic therapy with verteporfin: a novel treatment at the primary disease level. $\mathrm{Br} J$ Ophthalmol 2003; 87: 1453-1458.

54 Torres-Soriano ME, García-Aguirre G, Kon-Jara V, UstarizGonzáles O, Abraham-Marín M, Ober MD et al. A pilot study of intravitreal bevacizumab for the treatment of central serous chorioretinopathy (Case reports). Graefes Arch Clin Exp Ophthalmol 2008; 246: 1235-1239.

55 Seong HK, Bae JH, Kim ES, Han JR, Nam WH, Kim HK. Intravitreal bevacizumab to treat acute central serous chorioretinopathy: short-term effect. Ophthalmologica 2009; 223: 343-347.

56 Huang WC, Chen WL, Tsai YY, Chiang CC, Lin JM. Intravitreal bevacizumab for treatment of chronic central serous chorioretinopathy. Eye 2009; 23(2): 488-489.

57 Schaal KB, Hoeh AE, Scheurle A, Schuett F, Dithmar S. Intravitreal bevacizumab for treatment of chronic central serous chorioretinopathy. Eur J Ophthalmol 2009; 19(4): 613-617.

58 Golshahi A, Klingmüller D, Holz FG, Eter N. Ketoconazole in the treatment of idiopathic central serous chorioretinopathy. Meeting abstract 9/22/2004; Jahrestagung der DOG Deutsche Ophthalmologische Gesellschaft eV 2. Berlin.

59 Meyerle CB, Freund KB, Bhatnagar P, Shah V, Yannuzzi LA et al. Ketoconazole in the treatment of chronic idiopathic central serous chorioretinopathy. Retina 2007; 27: 943-946.

60 Gass JD. Specific diseases causing disciform macular detachment. Stereoscopic Atlas of Macular Diseases 1997; 1: 52-70.

61 Hayashi K, Hasegawa Y, Tokoro T. Indocyanine green angiography of central serous chorioretinopathy. Int Ophthalmol 1986; 9: 37-41.

62 Tittl M, Maar N, Polska E, Weigert G, Stur M, Schmetterer L. Choroidal hemodynamic changes during isometric exercise in patients with inactive central serous chorioretinopathy. IOVS; 2005; 46: 4717-4721.

63 Tittl M, Polska E, Kircher K, Kruger A, Maar N, Stur M et al. Topical fundus pulsation measurements in patients with active central serous chorioretinopathy. Arch Ophthalmol 2003; 121: 975-978.

64 Spitznas M. Pathogenesis of central serous retinopathy: a new working hypothesis. Graefe's Arch Clin Exp Ophthalmol 1986; 224: 321-324.

65 Negi A, Marmor MF. Experimental serous retinal detachment and focal pigment epithelial damage. Arch Ophthalmol 1984; 102: 445-449. 
66 Marmor MF. New hypothesis on the pathogenesis and treatment of serous retinal detachment. Graefe's Arch Clin Exp Ophthalmol 1988; 226: 548-552.

67 Lewis ML. Idiopathic serous detachment of the retinal pigment epithelium. Arch Ophthalmol 1978; 96: 620-624.

68 Laatikainen L, Hoffren M. Long-term follow-up study of nonsenile detachment of the retinal pigment epithelium. Eur J Ophthalmol 1991; 1: 79-84.

69 Mudvari SS, Goff MJ, Fu AD, McDonald HR, Johnson RN, Ai E, Jumper JM. The natural history of pigment epithelial detachment associated with central serous chorioretinopathy. Retina 2007; 27: 1168-1173.

70 Loo RH, Scott IU, Flynn Jr HW, Gass JD, Murray TG, Lewis ML et al. Factors associated with reduced visual acuity during long-term follow-up of patients with idiopathic central serous chorioretinopathy. Retina 2002; 22: 19-24.

71 Perkins SL, Kim JE, Pollack JS, Merrill PT. Clinical characteristics of central serous chorioretinopathy in women. Ophthalmology 2002; 109: 262-266.

72 Sawa T, Gomi F, Tano Y. Three-dimensional optical coherence tomographic findings of idiopathic multiple serous retinal pigment epithelial detachment. Arch Ophthalmol 2005; 123: 122-123.

73 Iida T, Hagimura N, Sato T, Kishi S. Evaluation of central serous chorioretinopathy with optical coherence tomography. Am J Ophthalmol 2000; 129: 16-20.

74 Montero JA, Ruiz-Moreno JM. Optical coherence tomography characterization of idiopathic central serous chorioretinopathy. Br J Ophthalmol 2005; 89: 562-564.

75 Mitarai K, Gomi F, Tano Y. Three-dimensional optical coherence tomographic findings in central serous chorioretinopathy. Graefe's Arch Clin Exp Ophthalmol 2006; 244: 1415-1420.

76 Hirami Y, Tsujikawa A, Sasahara M, Gotoh N, Tamura H, Otani A et al. Alterations of retinal pigment epithelium in central serous chorioretinopathy. Clin Experiment Ophthalmol 2007; 35: 225-230.

77 Gupta P, Gupta V, Dogra MR, Singh R, Gupta A et al. Morphological changes in the retinal pigment epithelium on spectral-domain OCT in the unaffected eyes with idiopathic central serous chorioretinopathy. Int Ophthalmol 2010; 30(2): 175-181.

78 Marmor MF, Tan F. Central serous chorioretinopathy: bilateral multifocal electroretinographic abnormalities. Arch Ophthalmol 1999; 117: 184-188.

79 Spaide RF, Hall L, Haas A, Campeas L, Yannuzzi LA, Fisher YL. et al. Indocyanine green videoangiography of older patients with central serous chorioretinopathy. Retina 1996; 16: 203-213.

80 Yoshioka H, Katsume Y. Experimental central serous chorioretinopathy: III. Ultrastructural findings. Jpn J Ophthalmnol 1982; 26: 397-409.

81 Jampol LM, Weinreb R, Yannuzzi L. Involvement of corticoseroids and catecholamines in the pathogenesis of central serous chorioretinopathy: A rationale for new treatment strategies. Ophthalmology 2002; 109: 1765-1766.

82 Carvalho-Recchia C, Yannuzzi L, Negrao S, Spaide RF, Freund KB, Rodriguez-Coleman $\mathrm{H}$ et al. Corticosteroids and central serous chorioretinopathy. Ophthalmology 2002; 109: 1834-1837.

83 Godel V, Blumenthal M, Regenbogen L. Retrobulbar neuritis and central serous chorioretinopathy. J Pediatr Ophthalmol 1977; 14: 296-298.
84 Chaine G, Haouat M, Menard-Molcard C. Central serous chorioretinopathy and systemic steroid therapy. J Fr Ophthalmol 2001; 24: 139-146.

85 Bouzas EA, Moret P, Pournaras CJ. Central serous chorioretinopathy complicating solar retinopathy treated with glucocorticoids. Graefes Arch Clin Exp Ophthalmol 1999; 237: 166-168.

86 Gass JD, Slamovits TL, Fuller DG, Gieser RG, Lean JS. Posterior chorioretinopathy and retinal detachment after organ transplantation. Arch Ophthalmol 1992; 110: 1717-1722.

87 Harada T, Harada K. Six cases of central serous choroidopathy induced by systemic corticosteroid therapy. Doc Ophthalmol 1985; 60: 37-44.

88 Matsunaga H, Nishimura T, Uyama N. Recent cases of multifocal posterior pigment epitheliopathy. Rinsho Ganka 1992; 46: 729-733.

89 Eckstein MB, Spalton DJ, Holder G. Visual loss from central serous retinopathy in systemic lupus erythematosus. Br J Ophthalmol 1993; 77: 607-609.

90 Tittl MK, Spaide RF, Wong D, Pilotto E, Yannuzzi LA, Fisher YL et al. Systemic findings associated with central serous chorioretinopathy. Am J Ophthalmol 1999; 128: 63-68.

91 Bouzas E, Karadimas P, Pournaras CJ. Central serous chorioretinopathy and glucocorticoids. Surv Ophthalmol 2002; 47: 431-448.

92 Chrousos GP, Gold PW. The concepts of stress and stress system disorders. Overview of physical and behavioral homeostasis. JAMA 1992; 267: 1244-1252.

93 Kvetnansky R, Pacak K, Fukuhara K, Viskupic E, Hiremagalur B, Nankova B et al. Sympathoadrenal system in stress. Interaction with the hypothalamic-pituitaryadrenocortical system. Ann NY Acad Sci 1995; 771: 131-158.

94 Haimovici R, Rumelt S, Melby J. Endocrine abnormalities in patients with central serous chorioretinopathy. Ophthalmology 2003; 110: 698-703.

95 Hadcock JR, Malbon CC. Regulation of 13-adrenergic receptors by 'permissive' hormones: glucocorticoids increase steady-state levels of receptor mRNA. Proc Natl Acad Sci USA 1988; 85: 8415-8419.

96 Sakaue M, Hoffman BB. Glucocorticoids induce transcription and expression of the a13B adrenergic receptor gene in DTT1 MF-2 smooth muscle cells. J Clin Invest 1991; 88: 385-389.

97 Makara GB, Haller J. Non-genomic effects of glucocorticoids in the neural system. Evidence, mechanisms and implications. Prog Neurobiol 2001; 65: 367-390.

98 Weenink AC, Borsje RA, Oosterhuis JA. Familial chronic central serous chorioretinopathy. Ophthalmologica 2001; 215: 183-187.

99 Fawzi AA, Holland GN, Kreiger AE, Heckenlively JR, Arroyo JG, Cunningham Jr ET. Central serous chorioretinopathy after solid organ transplantation. Ophthalmology 2006; 113: 805-813.

100 Iida T, Yannuzzi LA, Spaide RF, Borodoker N, Carvalho CA, Negrao S. Cystoid macular degeneration in chronic central serous chorioretinopathy. Retina 2003; 23: $1-7$.

101 Cardillo Piccolino F, De La Longrais RR, Ravera G, Eandi $\mathrm{CM}$, Ventre L, Abdollahi A et al. The foveal photoreceptor layer and visual acuity loss in central serous chorioretinopathy. AmJ Ophthalmol 2005; 139: 87-99. 
102 Cardillo Piccolino F, De La Longrais RR, Manea M, Cicinelli S. Posterior cystoid retinal degeneration in central serous chorioretinopathy. Retina 2008; 28: 1008-1012.

103 Cardillo Piccolino F, De La Longrais RR, Manea M, Cicinelli S, Ravera G. Risk factors for posterior cystoid retinal degeneration in central serous chorioretinopathy. Retina 2008; 28: 1146-1150.

104 Erickson PA, Fisher SK, Anderson DH, Stern WH, Borgula GA. Retinal detachment in the cat: the outer nuclear and outer plexiform layers. Invest Ophthalmol Vis Sci 1983; 24: 927-942.

105 Anderson DH, Guerin CJ, Erickson PA, Stern WH, Fisher SK. Morphological recovery in the reattached retina. Invest Ophthalmol Vis Sci 1986; 27: 168-183.

106 Chuang EL, Sharp DM, Fitzke FW, Kemp CM, Holden AL, Bird AC. Retinal dysfunction in central serous retinopathy. Eye 1987; 1: 120-125.

107 Mori T, Pepperberg DR, Marmor MF. Dark adaptation in locally detached retina. Invest Ophthalmol Vis Sci 1990; 31: 1259-1263.

108 Wang M, Munch IC, Hasler PW, Prünte C, Larsen M. Central serous chorioretinopathy. Acta Ophthalmol 2008; 86: 126-145.

109 Mata NL, Radu RA, Clemmons RC, Travis GH. Isomerization and oxidation of vitamin $\mathrm{A}$ in conedominant retinas: a novel pathway for visual-pigment regeneration in daylight. Neuron 2005; 36: 69-80.

110 Klein ML, Van Buskirk EM, Friedman E, Gragoudas E, Chandra S. Experience with nontreatment of central serous choroidopathy. Arch Ophthalmol 1974; 91: 247-250.

111 Bujarborua D. Long-term follow-up of idiopathic central serous chorioretinopathy without laser. Acta Ophthalmol Scand 2001; 79: 417-421.

112 Wong R, Chopdar A, Brown M. Five to 15 year follow-up of resolved idiopathic central serous chorioretinopathy. Eye 2004; 18: 262-268.

113 Koskela P, Laatikainen L, von Dickhoff K. Contrast sensitivity after resolution of central serous retinopathy. Graefes Arch Clin Exp Ophthalmol 1994; 232: 473-476.

114 Spaide RF, Campeas L, Haas A, Yannuzzi LA, Fisher YL, Guyer DR et al. Central serous chorioretinopathy in younger and older adults. Ophthalmology 1996; 103: 2070-2080.

115 Sahu DK, Namperumalsamy P, Hilton GF, de Sousa NF. Bullous variant of idiopathic central serous chorioretinopathy. Br J Ophthalmol 2000; 84: 485-492.

116 Gass JDM. Bullous retinal detachment - an unusual manifestation of idiopathic central serous choroidopathy. Am J Ophthalmol 1973; 75: 810-821.

117 Benson WE, Shields JA, Annesley Jr WH, Tasman W. Idiopathic central serous chorioretinopathy with bullous retinal detachment. Ann Ophthalmol 1980; 12: 920-924.

118 Schatz H, McDonald HR, Johnson RM, Chan CK, Irvine AR, Berger AR et al. Subretinal fibrosis in central serous chorioretinopathy. Ophthalmology 1995; 102: 1077-1088.

119 McLean JM, Gordon DM, Koteen H. Clinical experience with ACTH and cortizone in ocular diseases. Trans Am Acad Ophthalmol Otolaryngol 1951; 55: 565-575.

120 Purnell JE, Leopold IH. Cortisone in ocular diseases: Further studies. AmJ Ophthalmol 1952; 35: 663-670.

121 Hobbs HE. Macular degeneration treated with cortisone. Proc R Soc Med 1953; 46: 213-218.

122 Pecora JL. Ibuprofen in the treatment of central serous chorioretinopathy. Am J Ophthalmol 1978; 10: 1481-1483.
123 Bialasiewicz A. Uber therapeutische Erfolge bei Retinitis centralis serosa mit Priscoline- injektionen. Klin Monatsbl Augenheilkd 1957; 131: 536-537.

124 Burton T. Central serous retinopathy. In: FC Blodi (ed). Current Concepts in Ophthalmology. CV Mosby: St Louis, 1972, pp 1-28.

125 Leaver P, Williams C. Argon laser photocoagulation in the treatment of central serous retinopathy. $\mathrm{Br} J$ Ophthalmol 1979; 63: 674-677.

126 Watzke RC, Burton TC, Leaverton PE. Ruby laser photocoagulation therapy of central serous retinopathy. Trans Am Acad Ophthalmol Otolaryngol 1974; 78: 205-211.

127 Robertson D, Ilstrup D. Direct, indirect and sham laser photocoagulation in the management of central serous retinopathy. Am J Ophthalmol 1983; 95: 457-466.

128 Dellaporta A. Central serous retinopathy. Trans Am Ophthalmol Soc UK 1976; 74: 144-151.

129 Gilbert CM, Owens SL, Smith PD, Fine SL. Long-term follow-up of central serous chorioretinopathy. Br J Ophthalomol 1984; 68: 815-820.

130 Wang M, Sander B, la Cour M, Larsen M. Clinical characteristics of subretinal deposits in central serous chorioretinopathy. Acta Ophthalmol Scand 2005; 83: 691-696.

131 Robertson DM. Argon laser photocoagulation treatment in central serous chorioretinopathy. Ophthalmology 1986; 93: 972-974.

132 Ficker L, Vafidis G, While A, Leaver P. Long-term follow-up of a prospective trial of argon laser photocoagulation in the treatment of central serous retinopathy. Br J Ophthalomol 1988; 72: 829-834.

133 Sharma T, Shah N, Rao M, Gopal L, Shanmugam MP, Gopalakrishnan $\mathrm{M}$ et al. Visual outcome after discontinuation of corticosteroids in atypical severe central serous chorioretinopathy. Ophthalmology 2004; 111: 1708-1714.

134 Husain D, Kramer M, Kenny AG, Michaud N, Flotte TJ, Gragoudas ES et al. Effects of photodynamic therapy using verteporfin on experimental choroidal neovascularization and normal retina and choroid up to seven weeks after treatment. Invest Ophthalmol Vis Sci 1999; 40: 2322-2331.

135 Tarantola RM, Law JC, Recchia FM, Sternberg Jr P, Agarwal A. Photodynamic therapy as treatment of chronic idiopathic central serous chorioretinopathy. LasersSurg Med 2008; 40: 671-675.

136 Treatment of age related macular degeneration with Photodynamic Therapy (TAP) Study group. Photodynamic therapy of subfoveal choroidal neovascularization in age related macular degeneration with verteporfin. Arch Ophthalmol 1999; 117: 1329-1345.

137 Lee PY, Kim KS, Lee WK. Severe choroidal ischaemia following photodynamic therapy for pigment epithelial detachment and chronic central serous chorioretinopathy. Jpn J Ophthalmol 2009; 53: 52-56.

138 Lai TY, Chan WM, Lam DS. Transient reduction in retinal function by multifocal electroretinogram following photodynamic therapy. Am J Ophthalmol 2004; 137: 826-833.

139 Tzekov R, Lin T, Zhang KM, Jackson B, Oyejide A, Orilla $\mathrm{W}$ et al. Ocular changes after photodynamic therapy. Invest Ophthalmol Vis Sci 2006; 47: 377-385.

140 Lai TYY, Chan W-M, Li H, Lai RY, Liu DT, Lam DS. Safety enhanced photodynamic therapy with half dose verteporfin for chronic central serous chorioretinopathy: a short-term pilot study. Br J Ophthalmol 2006; 90: 869-874. 
141 Chan WM, Lai TYY, Lai RYK, Liu DT, Lam DS. Half dose verteporfin photodynamic therapy for acute central serous chorioretinopathy. Ophthalmology 2008; 115: 1756-1765.

142 Chan WM, Lai TYY, Lai RY, Tang EW, Liu DT, Lam DS. Safety enhanced photodynamic therapy for chronic central serous chorioretinopathy. Retina 2008; 28: 85-93.

143 Zhao MW, Zhou P, Xiao HX, Lv YS, Li CA, Liu GD et al. Photodynamic therapy for acute central serous chorioretinopathy: the safe effective lowest dose of verteporfin. Retina 2009; 29: 1155-1161.

144 Reibaldi M, Boscia F, Avitabile T, Russo A, Cannemi V, Uva MG et al. Low-fluence photodynamic therapy in longstanding chronic central serous chorioretinopathy with foveal and gravitational atrophy. Eur J Ophthalmol 2009; 19: 154-158.

145 Reibaldi M, Cardascia N, Longo A, Furino C, Avitabile T, Faro $\mathrm{S}$ et al. Standard-fluence versus low-fluence photodynamic therapy in chronic central serous chorioretinopathy: a nonrandomized clinical trial. Am J Ophthalmol 2010; 149: 307-315.

146 Inoue R, Sawa M, Tsuyikawa M, Gomi F. Association between the efficacy of photodynamic therapy and indocyanine green angiography findings for central serous chorioretinopathy. Am J Ophthalmol 2010; 149: 441-446.

147 Moon JW, Yu HG, Kim TW, Kim HC, Chung H. Prognostic factors related to photodynamic therapy for central serous chorioretinopathy. Graefes Arch Clin Exp Ophthalmol 2009; 247(10): 1315-1323.
148 Maruko I, Iida T, Sugano Y, Ojima A, Ogasawara M, Spaide RF. Subfoveal choroidal thickness after treatment of central serous chorioretinopathy. Ophthalmology 2010; 117(9): 1792-1799.

149 Chen SN, Hwang JF, Tseng LF, Lin CJ. Subthreshold diode micropulse photocoagulation for the treatment of chronic central serous chorioretinopathy with juxtafoveal leakage. Ophthalmology 2008; 115: 2229-2234.

150 Ricci F, Missiroli F, Regine F, Grossi M, Dorin G. Indocyanine green enhanced subthreshold diode-laser micropulse photocoagulation treatment of chronic central serous chorioretinopathy. Graefes Arch Clin Exp Ophthalmol 2009; 247: 597-607.

151 Gupta B, Elagouz M, McHugh D, Chong V, Sivaprasad S. Micropulse diode laser photocoagulation for central serous chorioretinopathy. Clin Experiment Ophthalmol 2009; 37: 801-805.

152 Lanzetta P, Furlan F, Morgante L, Veritti D, Bandello F. Nonvisible subthreshold micropulse diode laser $(810 \mathrm{~nm})$ treatment of central serous chorioretinopathy. A pilot study. Eur J Ophthalmol 2008; 18(6): 934-940.

153 Cadepond F, Ulmann A, Baulieu EE. RU486 (Mifepristone): Mechanisms of action and clinical uses. AnnuRevMed 1997; 48: 129-156.

154 Caccavale A, Imparato M, Romanazzi F, Negri A, Porta A, Ferentini F. A new strategy of treatment with low-dosage acetyl salicylic acid in patients affected by central serous chorioretinopathy. Med Hypotheses 2009; 73: 435-437. 